O Direito Positivo entende fazer-se mister que o trabalhador exerça sua atividade de 12 meses, no segundo período, para ter direito ao gôzo de férias. Entretanto, muitas vêzes o trabalhador, antes de completar o segundo período, deixa a emprêsa; seria então prejudicado. Então, os Tribunais do Trabalho vêm entendendo que, para o gôzo das férias no segundo período não se faz mister a sua atividade no transcurso dos doze meses integrais. Entretanto, uma vez que é Direito Positivo, os tribunais do trabalho, a julgarem por esta forma, estarão agindo contra a lei.

Levando em conta que o Direito do Trabalho é todo dirigido com a finalidade de beneficiar a classe menos favorecida pela fortuna os hipossuficientes, no dizer do professor Cesarino Júnior, de São Paulo - as Juntas de Conciliação e Julgamento vêm, de uns tempos a esta parte, humanizando a norma legal.

Acontece que, de qualquer forma, estão agindo contra a lei $e_{\text {, }}$ para evitar qualquer prejuízo aos trabalhadores, entendeu a Comissão que o Congresso Jurídico se deva dirigir ao Congresso Nacional, sugerindo seja legislado a respeito, transformando em Direito Positivo essas emanações da jurisprudência, que só vêm beneficiar o trabalhador nacional.

O SR. PRESIDENTE - Estão em discussão as conclusões do parecer apresentado "pela Comissão sôbre a tese do dr. Mozart Victor Russomano, expendidas pelo professor Dario Bittencourt.

(Pausa).

Ninguém querendo fazer uso da palavra para discutí-las, vou submetê-las a votos. Os srs. Congressistas que as aprovam queiram ficar sentados. (Pausa).

Aprovadas.

\section{"RUY E O DIREITO DO TRABALHO"}

\section{Dario de Bittencourt}

Docente-livre e Professor Catedrático, interino, de "Direito Industrial e Legislação do Trabalho" da Faculdade de Direito de Pôrto Alegre (da Universidade do Rio Grande do Sul).

(SÜMULA PARA DESENVOLVIMENTO ORAL)

1 - A vida apostolar de Ruy Barbosa; julgamento apressado de Gilberto Freyre.

a) Gilberto Freyre, "Inglêses”, pág. 169: “... Os problemas sociais quase não existiam para o glorioso campeão brasileiro do habeascorpus. Passou pela campanha da abolição como quem atravessou um corredor que apenas fôsse de uma ordem jurídica a outra, $\mathrm{Na}$ Federação - e na sua conseqüência: a República de 89 - só enxergou a questão política a desajustamentos que supunha fôssem entre nós os mesmos que na América inglêsa. No Civilismo, fêz-se paladina de uma causa que não era senão a dos românticos brasileiros das soluções jurídicas. Uma causa melancòlicamente vazia de sentido social e de realidade brasileira..."

b) Gilberto Freyre, "Voltando a Ruy Barbosa" e "Pela segunda vez voltando a Ruy", in "Correio do Povo", de P. Alegre, edições de 7 e 21 de maio de 1950: “...Os menos intransigentes na devoção a Ruy temos que continuar estranhando a indiferença em que o campeão do habeas corpus se manteve diante da questão social ou - excetuada a escravidão - das questões sociais de sua época e do seu país, só se tendo referido a elas no fim da vida, já valetudinário e incapaz de orientar, não direi uma "legislação social adiantada", mas simples reformas sociais num país, como o Brasil, desde a extinção da escravidão necessitando delas. Num país saído às tontas do regime do trabalho escravo para o de liberdade econômica".

2 - A abolição do trabalho servil e a atuação do acadêmico de direito, do advogado, do jornalista e do deputado Ruy Barbosa.

3 - O problema da habitação obreira e os preconícios de Ruy, através um parecer parlamentar (1892), voltando à carga mais tarde (1893) 
a) Ruy, "Obras Completas", vol. XIX, tomo II - $1892-$ pag. 237. - "Obras Completas", vol. X, tomo IV - 1893 - pag. 1.

4 - A questão social, a encíclica "Rerum Novarum" e o necrológio do papa Leão XIII, feito pelo senador Ruy Barbosa.

a) "Anáis do Senado Federal" 1903, vol. I, pag. 462

b) Leão XIII. "Rerum Novarum", Rio, 1950, edição Org. Simões, com palavras de Ruy Barbosa sôbre Leão XIII, pags. 3/5.

5 - O elogio do trabalho na obra de Ruy Barbosa.

a) Ruy Barbosa, "Oração aos Moços", ed. A. dos Reis, Rio, 1932, pág. $40 / 41$;

b) idem idem, in "Ensaios Literários", Rio, 1949, págs. 213/215;

c) idem idem, edição nacional da Casa de Ruy Barbosa, Rio, 1949, págs. $35 / 36$;

d) idem idem, edição do Serviço da Imprensa Universitária da URGS, 1949, págs. 17/19.

6 - A questão social e os Códigos Civis. Civil.

7 - A integração da Legislação Social no complexo do Código

8 - A elaboração do Código Civil Brasileiro e os problemas proletários.

a) Evaristo de Moraes, "Direito Operário", Rio, 1904, páa. 23 e 28 .

b) Ruy Barbosa, "Imprensa", vol. I, págs. 89/90.

c) contribuição do "Centro das classes operárias" (Proj. Cód. Civ., vol. III, págs. 33/35).

d) emendas relativas ao instituto da locação de serviços (Proj. III pág. 34).

e) "homestead"

f) solução para o problema da família irregular ( 6 anos $=$ casamento ou indenização)

g) exclusão da mulher casada do rol dos relativamente incapazes;

h) isenção do serviço da Guarda Nacional, em tempo de paz, ao operário;

i) fixação em lei do máximo do tempo de trabalho;

j) redução das horas de trabalho.

9 - Códigos Civis, - "códigos da burguesia e do capitalismo..."

Opiniões de: Georges Renard, Alfredo Palacios, Lacerda de Almeida, Evaristade Moraes e Pontes de Miranda.

$$
-1081-
$$

10 - A primeira conflagraçẫo mundial e as agitações obreiras.

11 - Os problemas proletários, pela vez primeira, têm guarida em uma Constituição - a Mexicana, de 31 de janeiro de 1917.

a) "Constitucion politica de los Estados Unidos Mexicanos", Mexico, 1927;

b) B. Mirkine-Guetzevitch, "Las nuevas constituciones del mundo" Editorial España, s/d, pags. 637.

12 - A revolução soviética (7 de novembro de 1917) e suas conseqüências para a classe obreira mundial.

13 - As agitações grevistas de 1917/1918, no Brasil, e sua repercussão no Congresso Nacional.

a) Evaristo de Moraes, "Direito Operário", págs. 78; 119/437;

- Legislação Social, 1, pág.

c) Alcides Maya, discurso na Câmara dos Deputados, sôbre "O projeto do Código do Trabalho", in "A Federação", de 1918.

14 - Projetos de cláusulas trabalhistas a inserir-se nos tratados de paz, elaborados durante a primeira conflagração mundial e depois do armistício de 11 de novembro de 1918.

a) Justin Godart, "Les clauses du travail dans les traité de Versailles" (28. juin. 1919).

15 - A primeira lei moderna brasileira sôbre Direito Operário: a de Acidentes do Trabalho (19 de janeiro de 1919).

a) Afrânio Peixoto, "Marta e Maria", pág. 311

b) Documentos Parlamentares - Legislação Social, I, 1. ${ }^{a}$ parte.

c) Afrânio Peixoto, opus cit., pág. 379/383 e pag. 439.

16 - Ruy Barbosa - legítimo precursor, inobstante olvidado injustamente, da Legislação Trabalhista Brasileira:

a) entrevista ao "Correio do Povo", de Pôrto Alegre, em 1919; sua ressonância na convenção presidencial (25.2.1919), através declaração de voto do senador Soares dos Santos, da bancada do Rio Grande do Sul;

b) conferência: "Às Classes Conservadoras", pronunciada na Associação Comercial do Rio de Janeiro, a 8 de março de 1919;

c) A famosa conferência "A Questão Social e a Política no Brasil", proferida no Teatro Lírico, do Rio de Janeiro (20 de março de 1919).

in Ruy Barbosa, "Campanha Presidencial", Bahia, 1919. 
17 - O operário no Direito Internacional: o tratado de paz de Versailles (28.6.1919) e as cláusulas trabalhistas nêle ensartadas (Parte XIII) e nos deSaint Germain (10.9.1919) e de Saint Quentin (? 1919)

a) Justin Godart, "Les clauses du travail dans le traité de Versailles"

18 - A remarcada influência social no Direito Político; a Constituição de Weimar (11 de agôsto de 1919).

a) Francisco Walker Linares, "Orientacioón del Derecho Social contemporâneo", pág. 58 ;

b) Francisco Alessandri Gimenez y otros, "Las actuales orientaciones del Derecho", 1919".

c) Ottmar Bühler, "La constitución alemana de 11 de agosto

19 - Normas trabalhistas nas modernas constituições, inclusive nas brasileiras, desde a reforma de 7 de setembro de 1926 até 18 de setembro de 1946.

a) B. Mirkine-Guetzévitch, "Les nouvelles tendances du Droit Constitutionnel", Paris, 1931;

b) Roger Bonnard, "La guerre de 1939/1940 et le Droit Public", Paris, 1940;

c) Georges Burdeau, "Manuel de Droit Public-Les libertés publiques, les droits sociaux";

d) A. Svolos, professeur à la Faculté de Droit d'Athènes, "Le Travail dans les Constitutions contemporaines", Paris, 1939;

e) Carlos A. Ayarragaray, "El destino del Derecho Procesal al término de la guerra", Buenos Aires, 1945 .

f) Paulino Jacques," "As inovações da Constituição de 1946 no domínio do Direito Social", in "Arquivos do Instituto de Direito Social", vol. $9 /$ n. ${ }^{\circ} 1$; págs. $85 / 91$;

g) Nelson Marcondes Amaral, "O Direito Internacional Social no plano Simonsen", in cit. "Arquivos", págs. 113/121;

20 - Se fôra Ruy, um dia, Presidente... (conclusão).

\section{CONCLUSÃO}

Ruy Barbosa não poderia ter ficado, como não ficou, em que peze o ponto de vista de. Gilberto Freyre, estranho aos anseios da massa obreira do Brasil.

Ouviu-lhe sempre os anseios; escutou-lhe queixas e reclamos e por ela, desde estudante de direito, se interessou - como excele de sua atuação a prol da abolição da escravatura.
Buscou dar-lhe habitação condigna, víveres de boa qualidade, água pura e abundante ar, em conformidade, aliás, com o sábio precocínio de Lord Beaconsfield, primeiro ministro do Reino Unido da Grâ-Bretanha, Escócia e Irlanda.

Jurista emérito, perfeitamente em dia com todos os problemas sociais, foi, por outro lado, testemunha ocular das agitaçóes grevistas de 1917/1918, no Rio de Janeiro.

Não poderia desconhecer a Constituição Mexicana de 31 de janeiro de 1917; não poderia ter se despreocupado da revolução soviética de 7 de novembro de 1917 e seus efeitos na massa obreira internacional; não poderia ter ficado estranho aos debates parlamentares travados no Brasil, versando sôbre a instituição, em nos"so país, de um "Código do Trabalho".

E que a nada disso foi estranho e, bem ao revés, que de tudo se apercebeu, demonstrou, exìmiamente, em sua magistral conferência no Teatro Lírico, do Rio de Janeiro, à noite de 20 de março de 1919 - meses antes da assinatura do tratado de paz de Versailles. Nessa conferência, traçou êle os rumos do Direito do Trabalho do Brasil.

Assim, "SE FÔRA RUY, UM DIA, PRESIDENTE DO BRA SIL", o nosso Direito do Trabalho teria sido introduzido na sistemática nacional, pelo menos, DEZ ANOS ANTES DE 1930.

Conseguintemente, apressado e injusto foi e continua a ser o julgamento de Gilberto Freyre sôbre Ruy Barbosa - "quod erat demonstrando".

Pôrto Alegre, 11 de agosto de 1950.

\section{CONGRESSO JURIDICO DE PÔRTO ALEGRE - SALA DAS \\ SESSÕES DA 9. ${ }^{a}$ COMISSÃO - DIREITO INDUSTRIAL E} LEGISLAÇÃO DO TRABALHO

\section{TESE DO PROFESSOR DARIO DE BITTENCOURT: "RUY E O DIREITO DO TRABALHO".}

\section{INDICAÇÃO}

A comissão, pela unanimidade de seus membros, e tendo em vista o PARECER oral apresentado pelo Relator, professor Magdaleno Girão Barroso

\section{RESOLVE}

A) não sòmente louvar o brilhante trabalho apresentado pelo professor DARIO DE BITTENCOURT, uma vez que representa uma 
das mais importantes contribuições ao esclarecimento que da obra de RUY BARBOSA se vem fazendo a partir da comemoração de seu centenário;

B) como recomendá-lo à aprovação do plenário do Congresso, com o destaque prevista pela parágrafo único do art. 13 do Regulamento, para que o seu ilustre autor tenha ocasião de especialmente esplaná-lo, restaurando, assim, de público, e com reflexo na opinião nacional, a verdade a respeito da co-participação do insigne polígrafo baiano na obra de estruturação da nossa legislação social;

C) e ainda, por fim, solicitar que seja incluído nos Anais, que do Congresso venham a ser publicados, encaminhando-se um exemplar à CASA DE RUY BARBOSA, para que nos seus arquivos possa figurar.

Pôrto Alegre, 15 de agosto de 1950.

Magdaleno Girão Barroso (Fac. Dir. Ceará) Henrique Stodieck (Fac. Dir. Florianópolis) M. S. Aurvalle

Mozart Vicior Russomano (Fac. Dir. Pelotas)

\section{DEBATES EM PLENÁRIO}

O SR. PRESIDENTE Prof. José Salgado Martins - Há sôbre a mesa, a tese "RUY E O DIREITO DO TRABALHO", de autoria do Dr. Dario de Bittensourt, e que tem por relator o Dr. Magdaleno Girão Barroso.

O SR. GIRÃO BARROSO - Excelentíssimo sr. Presidente, snrs, Congressitas, minhas senhoras, meus senhores.

O meu relatório vai ser, - como já o foi na Comissão, - ùnicamente oral, pois que, por uma feliz coincidência, eu já havia tratado exatamente, precisamente, do assunto, num trabalho escrito para a comemoração do centenário de RuyBarbosa, inserto na "Revista da Faculdade de Direito do Ceará".

Nesse trabalho - intitulado "Diretrizes sociais, econômicas e financeiras de Ruy Barbosa" - tive ocasião de estudar o assunto rigorosamente, não só nas obras sôbre a vida do grande político baiano, como na própria fonte original. Tais idéias eu alí havia expendido, quer no que concerne aos problemas gerais de economia finanças, quer no que respeita aos problemas sociais e, mais particularmente, aos problemas relacionados com o Direito do Trabalho. De maneira que, em virtude disso, me abstive de escrever algo de novo a propósito do assunto para justificar a tese, o estudo do meu eminente colega professor Dario Bittencourt, intitulado "Ruy e
- Direito do Trabalho", tese na qual o seu autor, de maneira brilhante, incisiva e mais que oportuna, contradiz uma afirmação injustamente feita a respeito de Ruy, pelo conhecido sociólogo Gilberto Freyre, afirm̂ação essa imperativamente feita, quer no seu livro "Inglêses no Brasil", quer em artigos para a imprensa, aqui mesmo publicados.

\section{Diz Gilberto Freyre:}

“... Os problemas sociais quase não existiam para o glorioso campeão brasileiro do hábeas-corpus. Passou pela campanha da Abolição como quem atravessou um corredor que apenas fosse de uma ordem jurídica a outra. $\mathrm{Na}$ Federação - e na sua conseqüência: a República de 89 - só enxergou a questão política a desajustamentos que supunha fôssem entre nós os mesmos que na América inglêsa. No Civilismo, fêz-se paladino de uma causa que não era senão a dos românticos brasileiros das soluções jurídicas. Uma causa melancòlicamente vazia de sentido social e de realidade brasileira..." ("INGLEESES". pág. 169).

“... Os menos intransigentes na devoção a Ruy temos que continuar estranhando a in dif e re $\mathrm{n}$ ç a em que o campeão do habeas-corpus se manteve diante da Ouestão Social ou - excetuada a Escravidão - das questões sociais de sua época e do seu país, só se tendo referido a elas no fim da vida, já valetudinário e incapaz de orientar, não direi uma "Legislação Social adiantada", mas simples reformas sociais num país, como o Brasil, desde a extinção da escravidão necessitando delas. Num país saído às tontas do regime do trabalho escravo para o de liberdade economica". ("Voltando a Ruy Barbosa", in "Correio do Povo", de Pôrto Alegre, 7 de maio de 1950).

Meus senhores, só se poderá justificar realmente uma afirmativa destas, (e é o que deflui o trabalho do professor Dario Bittencourt), ou porque Gilberto Freyre se haja precipitado no seu conceito, não tendo conhecimento pleno dêste aspecto da obra de Ruy ou porque pretendesse, porventura, fazer uma confusão ou uma identidade impossível entre a questão social e o socialismo. Porque, de outro modo, não fôra possível escrever o que êle escreveu, e se o tivesse feito ainda durante a vida de Ruy, decerto êsse grande homem, essa inteligência tão polimorfa, teria se defendido mais que suficientemente, como certa vez se defendeu da afirmação de que nunca soubera advogar a causa do operariado. Nessa defesa contra a increpação que lhe havia sido feita, escreveu Ruy uma de suas páginas mais belas:

"Dêsses mesmos antros morais, da caverna dessas consciências. de visco peçonho, saiu também a minha inimizade aos operários. Mãe mentira desbanca na maternidade os ratos. Cada manhã uma 
ainhada. Onde o princípio de liberdade, onde o princípio de igualdade, onde o princípio de fraternidade, que, nesta terra, me deixasse jamais de ver a seu lado?

"Mas que importa? Quanto mais notória a verdade, hais mexitória a obra dos aduladores. $\mathrm{Na}$ sorte do operário culminam três problemas capitais: a justiça, a instrução, a nobilitação do trabalho. Eu tive o batismo de minha carreira profissional, pleiteando, gratuitamente, na tribuna criminal, a justiça para uma inocente filha do povo, desonrada por um argentário, cujo dinheiro zombava dos tribunais; e Deus permitiu que, com ser ainda tão desautorizada a minha voz no seu primeiro ensaio, não bastasse a opulência do ricaço para subtrair ao castigo legal o poderoso libertino. "A minha obra de empenho nas câmaras imperiais, foi a reforma do ensino público, trabalho que mereceu ser proclamado na Europa como o mais considerável de todos os até alí existentes na história do parlamento brasileiro. E quem teria ido mais longe do que eu em serviços das classes trabalhadoras do Brasil, se a política, nos quase quarenta anos de então a hoje, em vez de me pilhar ali à-toa as idéias, houvesse dado à instrução popular o desenvolvimento com que o meu projeto a organizava? A maldição das classes laboriosas, entre nós, era a propriedade servil; e eu, desde 1869, me inscrevi entre os primeiros precursores de sua extinção radical, erguendo, primeiro do que ninguém, em São Paulo, o brado público do abolicionismo, a que servi nos mais avançados postos até sua vitória final, dezenove anos depois. Quem, portanto, no Brasil, lutou mais pela regeneração do trabalho?"

Esta resposta de Ruy Barbosa demonstra, da maneira mais eloqüente possível, que êle, durante os seus trabalhos e a sua vida tão intensa, jamais deixou de se preocupar com as classes sofredoras, com os humildes, e quando a questão social surgiu no Brasil, êle se tornou, mesmo, um de seus vanguardeiros, procurando, antes de mais ninguém, advogar o revisionismo da nossa Constituição, no sentido de permitir, de dar ensanchas a que fôssem reguladas por leis públicas, as relações entre o Capital e o Trabalho.

Eu não quero ir mais longe na minha exposição, aprovando plenamente, de acôrdo aliás, com o ponto de vista unânime da Comissão, a tese do meu ilustre colega, visto que êle terá ocasião, logo depois de mim, demasiadamente, de expor a sua investigação a respeito do assunto. Quero apenas lembrar a esta Casa que durante a campanha presidencial de 1919, os partidários de Epitácio Pessôa, seu opositor, negavam terminantemente a possibilidade do Estado intervir, com suas leis, na discórdia entre Capital e Trabalho, batendo-se constantemente pela prevalência da doutrina individualista e privatística.
Ruy, entretanto, no mesmo tempo, na mesma época, pleiteou a revisão da Constituição, dizendo que só o espírito atravessado nos domínios austrais poderia contrapor-se agora à evolução geral do mundo, arrastada em torrentes com os conceitos de socialismo, negando, com êstes erros categóricos, a lei ou arbítrio de interferir nas controvérsias entre obreiros e patrôes.

Vejam senhores, um homem que isso afirma e que chegou, por estas afirmações, até a ser taxado de comunista, um homem dêsses continua hoje negado e incompreendido, por uma das maiores penas da nossa intelectualidade, o que ainda mais grave torna a afirmativa

O SR. ALCIDES DE MENDONCA LIMA - Aliás o Sr. Gilberto Freyre tem sido injusto para com Ruy Barbosa em tôdas as suas manifestações; reiteradamente injusto.

O SR. MOZART VICTOR RUSSOMANO - O professor Gilberto Freyre, de fato, foi um crítico rigoroso ao ponto de vista de Ruy Barbosa em face do Direito do Trabalho, porque fêz um confronto, quanto à ação, no terreno dos problemas sociais, entre Ruy Barbosa e Nabuco.

O SR. ALCIDES DE MENDONÇA LIMA - Questão de ponto de vista.

O SR. MOZART VICTOR RUSSOMANO - E' questão do modo pelo qual os dois estadistas brasileiros desenvolveram as suas grandes e radiosas vidas.

O SR. GIRÃO BARROSO - De maneira que, para terminar, diria apenas que, na campanha de 1919, expandindo suas idéias numa plataforma política, nos discursos que fêz às classes conservadoras e às classes trabalhistas, Ruy Barbosa advogou quase todos os privilégios de que hoje desfrutam as classes trabalhadoras, batendo-se - como disse João Mangabeira em seu livro "Ruy, o estadista da República" - pelos problemas da habitação operária, trabalho de menores, da jornada de trabalho, do trabalho das mães operárias, acidentes no trabalho, do seguro-operário, da igualdade de sexo no trabalho, do salário mínimo, do trabalho noturno, do trabalho em domicílio; enfim, tudo quanto a mais avançada Legislação Social pudesse prever, foi discutido com a minudência e proficiência com que em 83, discorrera sôbre as instituições de ensino.

Portanto, meus senhores, a tese do meu ilustre e prezado colega Dario Bittencourt, está mais do que justificada e explicada, correspondendo, aliás, à afirmativa do grande biógrafo de Ruy quando diz que ninguém como êste viu no Brasil, tão cedo e tão longe, os problemas sociais. (Muito bem), (palmas).

O SR. DARIO DE BITTENCOURT - Peço a palavra, sr. Presidente. 
O SR. PRESIDENTE - Concedo a palavra ao nobre Congressista.

O SR. DARIO DE BITTENCOURT - Seuhor Presidente; senhores Congressistas, senhores professôres, minhas senhoras, meus senhores.

Teríamos imenso gôsto de desenvolvèr, com maior amplitude, o modesto trabalho que tivemos oportunidade de apresentar a êste Congresso; porém, como o tempo urge e grande número de teses está sôbre a mesa, e outras para vir a plenário, não desejamos por isto, nos alongar por mais tempo.

Entretanto, queremos, ainda que sintèticamente, após o brilhante relatório do eminente colega e amigo professor Girão Barroso, da Faculdade de Direito do Ceará, esquematizar o plano do trabalho que ao Congresso apresentamos.

Partindo das premissas de que o sociólogo brasileiro sr. Gilberto Freyre, reiteradamente, em livros e artigos de jornal, entendeu não ter Ruy Barbosa se preocupado com os problemas sociais do trabalhador brasileiro, procuramos, penetrando naquela selva que é a obra de Ruy, encontrar elementos em contrário, para concluir da seguinte forma: se Ruy Barbosa tivesse sido eleito Presidente da República, por volta do ano de 1920, então a Legislação Social Trabalhis ta Brasileira, que ingressou a jacto no nosso elenco jurídico, dez anos antes, nêle teria penetrado.

Verificamos, assim, sem nos preocupar com o trabalho de Ruy em prol da abolicão do trabalho servil, que já no ano de 1882 o grande brasileiro batalhava no seio do Congresso Nacional, em prol da habitação operária, procurando, num luminoso parecer, fazer com que o Poder Público se preocupasse com êsses problemas, até então desconhecidos do nosso Parlamento.

Em seguida, anos mais tarde, por ocasião de apresentar um outro parecer, versando sôbre questões de ensino, Ruy teve ensêjo de, mais uma vez, focar o problema e desenvolvê-lo com outra amplitude, preocupando-se não só com a habitação, mas, também, com o vestuário e o problema das férias operárias.

Em 15 de maio de 1891 foi publicada a famosa encíclica "Rerum Novarum" do Santo Padre Leão XIII, que é considerada, justamente, como a carta católica do trabalho. Ruy Barbosa interessou-se pelo assunto e quando foi do trespasse do grande antistite, em sessão do Senado Federal, aos 21 de julho de 1903, teve oportunidade de render pública homenagem a "alma ismpática às grandes questões sociais".

Em passagens as mais diversas da obra de Ruy Barbosa encontra-se o elogio do braço obreiro, das mãos calosas do proletário e, em artigo inserido na "A Imprensa", em data de 11 de outubro de 1898, anunciando dever ser votado, naquele dia, no Senado, o projeto regulando a locação do serviço agrícola, fez sua profissão de fé contrária a tôda e qualquer regulamentação de serviços, por implicar em diminuição da liberdade individual e em um constrangimento incompatível com o trabalho verdadeiramente livre.

"Magna pars" na feitura do Código Civil, Ruy Barbosa não poderia desconhecer a contribuição trazida aos respectivos trabalhos, pelo "Centro das classes operárias", bem assim como as discussões travadas acêrca do instituto da locação de serviços.

O ano de 1917, em plena conflagração européia, foi de ermarcada repercussão no panorama jurídico mundial, com reflexos no Brasil: a 31 de janeiro, o México promulga a sua Constituição - onde, pela vez primeira, os problemas laborais têm guarida em uma Lei Magna; a 7 de novembro é vitoriosa a revolução soviética e, no nosso país, especialmente em Rio, São Paulo, Santos, Recife e Pôrto Alegre, eclodem violentos movimentos grevistas; o deputado Mauricio Lacerda, buscando uma atitude de transigência com as classes obreiras, apresenta à Câmara dos Deputados um projeto de CÓDIGO DO TRABALHO. Será possível que Ruy Barbosa a tudo estivesse alheio, de olhos fechados e de ouvidos moucos?...

A resposta, dá-no-la o próprio Ruy, através monumental conferência versando sôbre "A Questão Social e a Política no Brasil", proferida no Rio de Janeiro, no Teatro Lírico, a 20 de março de 1919 - antes, consequentemente, da assinatura dos diversos tratados de paz que deram fim à primeira conflagração mundial, e, onde uma parte importantíssima, a Parte XIII, tôda ela é dedicada aos problemas operários, por isto que, para a maioria dos parlamentares e dos jornalistas, importava em verdadeira "novidade", com idéias anteriormente só proferidas pelos leaders operários em seus sindicatos e em seus comícios - Ruy Barbosa alçou a bandeira de revisão constitucional, para empreender-se uma "segunda emancipação" a prol dos trabalhadores do Brasil, profligando a República que, reacionàriamente, "inhersa desde o comêço no egoísmo da política do poder pelo poder, traidora desde o seu comêco aos seus compromissos, tinha muito em que ocupar a sua gente, para ir esperdiçar o tempo com assuntos sociais"...

E, buscando amparo para sua candidatura, após prolongadas considerações, assim peróra: "Operários brasileiros, se não renunciais à vossa terra, olhai, enquanto seja tempo, pela vossa Pátria!”

Teria sido, acaso, Ruy, um displicente, frente a questão social?...

Gostariamos imensamente de prosseguir nesta série de considerações ,afim de, repisando, deixar perfeitamente esclarecido que, mui ao revés, desde os agraços, sempre se preocupou com a vida 
e o bem estar do operário brasileiro; mas acontece que o tempo urge e, por isto mesmo, dando por palidamentejustificada e obscuramente defendida a tese proposta, concluiremos, agora, na presunção de ter esclarecido que Ruy Barbosa - em que péze a opinião reiterada do sr. Gilberto Freyre a respeito - jamais esteve "indiferente" face à Questão Social, eis que, contràriamente, sempre pôz em equação os problemas obreiros, buscando para os mesmos uma solução equidosa e justa! (Palmas).

O SR. PRESIDENTE - Antes de passar à tese seguinte, deveremos pôr em votação as conclusões do parecer apresentado pelo relator, dr. Girão Barroso, sôbre a tese do professor Dario Bittencourt - "Ruy e o Direito do Trabalho". O sr. secretário terá a bondade de ler as conclusões, para que o Congresso as tenha presentes.

O SR. SECRETÁRIO - (Lê):

"A comissão pela unanimidade de seus membros, e tendo em vista o PARECER oral apresentado pelo Relator, professor Magdaleno Girão Barroso

\title{
RESOLVE
}

A) não sòmente louvar o brilhante trabalho apresentado pelo professor DARIO BITTENCOURT, uma vez que representa uma das mais importantes contribuições ao esclarecimento que da obra de RUY BARBOSA se vem fazendo, a partir da comemoração de seu centenário;

B) como recomendá-lo à aprovação do plenário do Congresso, com o destaque previsto pelo parágrafo único do art. 13 do Regulamento, para que o seu ilustre autor tenha ocasião de especialmente explaná-lo, restaurando, assim, de público, e com reflexo na opinião nacional, a verdade a respeito da co-participação do insigne. polígrafo baiano na obra de estruturação da nossa legislação social;

C) e ainda, por fim, solicitar que seja incluído nos Anais, "que." do Congresso venham a ser publicados, encaminhando-se um exemplar à CASA DE RUY BARBOSA, para que nos seus arquivos possan figurar".

(Deixa a presidência o professor Salgado Martins, sendo subs-. tituído pelo professor Darcy Azambuja).

O SR. PRESIDENTE - Está em discussão o parecer dà Comissão. (Pausa).

Como ninguém quer fazer uso da palavra, passa-se à votação. Os srs. Congressitas que não estiverem de acôrdo, tenham a bondade
de se levantar. (Pausa). Aprovado.

\section{SESSÃO SOLENE DE ENCERRAMENTO DO CONGRESSO JURIDICO}

\author{
Realizada a 17 de agôsto de 1950
} sob a Presidência do Prof. Dr. Júlio César Bonnazzola

O SR. PRESIDENTE - Júlio César Bonnazzola - Vamos dar início à sessão de encerramento oficial do Congresso.

Tem a palavra o sr. professor Edgar Luiz Schneider.

O SR. EDGAR LUIZ SCHNEIDER - (Lendo):

A promoção dêste congresso não visou, apenas, a aproximação entre os homens do direito, senão também ao intuito de conferir, ao cabo de meio-século da Faculdade, que o ensina, os rumos nos quais se louvam seus mestres e as tendências nas quais se espelha a evolução jurídica do mundo.

Encargos dessa eminência, que tanto variam nas suas fontes geradoras, nunca terão um patrocínio, talvez, mais à feição, que entre os titulares do magistério. Não vai nisso um enaltecimento sem causa. São muitos, e todos de brios análogos, os cultores da ciência de Ulpiano, tais os legisladores, que a enriquecem, os advogados que interpretam e os juízes que a aplicam.

\section{O MAGISTÉRIO DO DIREITO}

Mas, os professôres que, nas práticas de uns e autros, buscam as provisões, valorizadas pela intuição e pela experiência, não só as coordenam, que ainda as depuram e propagam. Nessa faina diuturna, que remonta às nascentes do direito e se purifica nas suas águas perenes, em demanda da justiça, o mestre adulçora e irradia o fervor predicante.

Empossado nesses atributos, é de admitir-se, pois, que ao docente caiba, antes que aos demais, o afã de acolher as conquistas jurídicas e servir à sua difusão, entre as gerações que se sucedem.

Todavia, onde melhor o pudera, sentindo ao perto as frágoas da luta, senão ao contato do magistrado e profissionais do fôro, como familiares que são da rotação social do direito, em cuja primado assenta o destino da civilização? 